\title{
Assessment of Radiotherapy Treatment Field on Portal Film Using Image Processing
}

\author{
Nouf Abuhadi ${ }^{1}$, Ali Bakry Abdoelrahman Hassan ${ }^{2}$ \\ ${ }^{1}$ Radiology Department, College of Applied Medical Science, Jazan University, Jazan, KSA \\ ${ }^{2}$ Radiotherapy Department, College of Medical Radiological Science, Sudan University of Science and Technology, Khartoum, Sudan \\ Email: abdoelrahmanhassan@gmail.com
}

How to cite this paper: Abuhadi, N. and Abdoelrahman Hassan, A.B. (2019) Assessment of Radiotherapy Treatment Field on Portal Film Using Image Processing Open Journal of Biophysics, 9, 267-275. https://doi.org/10.4236/ojbiphy.2019.94019

Received: August 10, 2019

Accepted: September 26, 2019

Published: September 29, 2019

Copyright $\odot 2019$ by author(s) and Scientific Research Publishing Inc. This work is licensed under the Creative Commons Attribution International License (CC BY 4.0).

http://creativecommons.org/licenses/by/4.0/

\begin{abstract}
Many factors contribute to the accuracy of delivered dose to patients in external-beam radiotherapy (EBRT). Although some of these factors can be checked by implementing suitable quality control procedures, the main aim was to assess the radiotherapy treatment filed on portal film using image processing technique in order to increase the accuracy of treatment delivery to the tumor by measuring the actual $\mathrm{F} / \mathrm{S}$, dose uniformity and penumbra size using portal film. This research is conducted at radiation therapy department, Khartoum Oncology Center (RICK), Khartoum state, Sudan, from July-2014 up to December-2014. The field size of each type of radiotherapy $\mathrm{Co}^{60}$ is measured as $(9.4 \times 9.4) \mathrm{cm}$ and $(9.1 \times 9.1) \mathrm{cm}$, for linear accelerator machines it was $10 \times 10 \mathrm{~cm}$ exactly as the reference field size, and there is no area reduced in linacs. The penumbra size for the two types of $\mathrm{Co}^{60}$ machine was measured also and it was $1.2 \mathrm{~cm}$ and $1.0 \mathrm{~cm}$, and penumbra size of the linear accelerator machines was found to be $4 \mathrm{~mm}$. The area of the field that received radiation by $100 \%$ was measured and it was $94.1 \%$ and $91.1 \%$ in $\mathrm{Co}^{60}$ and $100 \%$ for linear accelerator machine and that means linacs deliver the $100 \%$ of the dose to the useful field size. The dose percentage in the field for $\mathrm{Co}^{60}$ was $98.0 \%$ and $94.1 \%$ and thus the dose in the border of field $83.1 \%$ and $89.0 \%$ and it's different in linacs because the dose percentage in the field was $78.4 \%$ and $78.4 \%$ and there is no measurable dose outside its field. Penumbra $\mathrm{Co}^{60}$ machines are relatively large which increase radiation dose to normal tissue and reduce the TCP, so calculation and accuracy of such calculation are necessary to the patient in term of NTCP.
\end{abstract}

\section{Keywords}

Films, Image Processing, Radiotherapy, RICK, Malignancy, IDL, Oncology 


\section{Introduction}

Teletherapy cobalt-60 units were first used for patient treatment in 1951 in Canada [1] [2]. Cobalt-60 was manufactured by irradiating cobalt-59 in a high neutron flux nuclear reactor. The main reasons for its suitability for teletherapy are the availability of relatively small, high specific activity, sources that reduce the beam penumbra; its relatively long half-life (5.27 years); and the almost monochromatic high-energy photon emission (photons of $1.173 \mathrm{MeV}$ and 1.333 $\mathrm{MeV}$ in equal quantity) [3].

Various beam collimators designs exist to give variable rectangular fields with sides ranging in length, typically, from $4 \mathrm{~cm}$ to $30 \mathrm{~cm}$ or even up to $40 \mathrm{~cm}$ on isocentric units with a source axis distance (SAD) of $100 \mathrm{~cm}$. Each of the four collimator leaves is usually focused on the edge of the source proximal to it, so as to avoid cut-off of the primary beam and minimize penumbra. Distances from the source to the far edge of the collimators are typically between $40 \mathrm{~cm}$ and 50 $\mathrm{cm}$ for machines designed for $80 \mathrm{~cm} \mathrm{SSD}$, but this distance may be increased by penumbra trimmers that are particularly desirable when the machine is to be used for $100 \mathrm{~cm}$ SSD treatment [3].

Field Size: can be defined as the measure of an area irradiated by a given beam; there are two most useful conventions. The first is the geometric field size; The geometric projection on a plane perpendicular to the central ray of the distal end of the collimator is as seen from the center of the front surface of the source. The second is the physical field size, defined as the area included within the 50 percent maximum dose isodose curve at the depth of maximum dose [4].

While the Penumbra size: The penumbra for electron beams is defined either in terms of the distance between two isodose values on a beam profile at the depth of maximum dose (or at the standard measurement depth), or indirectly in terms of distances between specified isodose and the geometric field edge under stated conditions as above. If the former, then generally the $20 \%-80 \%$ width is expected to be $10 \mathrm{~mm}$ to $12 \mathrm{~mm}$ for electron beams below $10 \mathrm{MeV}$, and $8 \mathrm{~mm}$ to $10 \mathrm{~mm}$ for electron beams between $10 \mathrm{MeV}$ and $20 \mathrm{MeV}$. These values apply for applicators with the final collimation stage at $5 \mathrm{~cm}$ or less from the skin, but for greater separation between the applicator and the skin the penumbra will increase. With careful design of the collimation system and a $15 \mathrm{~mm}$ diameter source, a penumbra of no more than $10 \mathrm{~mm}$ (distance between the $20 \%$ and $80 \%$ decrement lines) may be achieved at $5 \mathrm{~cm}$ depth for field sizes with an area of less than $400 \mathrm{~cm}^{2}$ [3].

The process of image manipulation in medical imaging was recently introduced as a very important issue in case of image processing; in this case we used this disciplines in case of calculating and accurately identifying the penumbra profile rather than using of conventional method such as QA programs and portal film in collaborations with treatment machine.

Linear accelerator is considering to have very excellent geometrical accuracy when it compared with $\mathrm{Co}^{60}$ machine and the presence of penumbra is relatively 
large in $\mathrm{Co}^{60}$ and it depend on the source size, depth, SDD and source diaphragm distance [4]. This research aimed to answer important questions which are; is it possible to have best assessment of radiotherapy treatment field? Does this method give the exact determination of radiation field size and penumbra size? Does this method give the correct value of uniformity?

\section{Review of Literature}

[5] stated that the field size that calculated by computerized score using Matlab program was $9.9 \pm 0.36049 \mathrm{~cm} \times 9.9 \pm 0.1123 \mathrm{~cm}$ calculated form digitized film. [6], aimed to verify radiotherapy treatments: computerized analysis of the size and shape of radiation fields using portal imaging. [7] studied the high energy linear accelerator penumbra size using the Pencil Beam Convolution algorithms and self-developing Gafchromic ${ }^{\mathrm{TM}}$ EBT2 film, he found that increased energy, field size and depth rise to an increased penumbra (20\%-80\%) width. For a 6 MV photon energy, the penumbra widths $(20 \%-80 \%)$ at $1.5 \mathrm{~cm}, 5 \mathrm{~cm}$, and 10 $\mathrm{cm}$ depths were $4.2 \mathrm{~mm}, 4.4 \mathrm{~mm}$, and $5.7 \mathrm{~mm}$ for the eclipse calculations and 2.9 $\mathrm{mm}, 4.1 \mathrm{~mm}$, and $4.2 \mathrm{~mm}$ for the EBT2 film measurements for $10 \times 10 \mathrm{~cm}$ field sizes, respectively.

\section{Materials and Methods}

This study conducted at radiation oncology center (RICK) to assess the radiation filed size uniformity and calculating the penumbra profile. radiographic images with Linear accelerator machine (ELECTA) $10 \mathrm{Mv}$, and two types of cobalt-60 machines Co-60 1) EQUINOX source size $2.5 \times 1.5 \times 1.5 \mathrm{~cm}$ Active size $1 \times 1 \times$ $1 \mathrm{~cm}$ and the second type Co-60 2) MDS source size $1 \times 1 \times 1 \mathrm{~cm}, 0.75 \times 0.75 \times$ $0.75 \mathrm{~cm}$, with Focus $1 \mathrm{~cm}$; performed using the verification film subjectively by placing a ready pack direct exposure film on the table on the SAD. With the collimator angle set at $0^{\circ}, 10 \times 10 \mathrm{~cm}$ square light fields obtained and the edges marked with a radiopaque object or a ballpoint pen by drawing lines on the film jacket with sufficient pressure to scratch the emulsion. Then the film was exposed for 1 - 2 min to obtain an optical density in the linear range of its sensitometric curve, usually around (1). Two more exposures at the collimator angles of $+90^{\circ}$ were made using fresh area of the same film or another film. The film processed in an automatic rapid processor. With millimeter graph paper attached to the patient treatment table raised to the nominal isocenter distance, the gantry was orientated to point the collimator axis of rotation vertically downward. Radiographic film to obtain an optimal radiographic density according to usable factor in all machines. Illustrating the $10 \times 10 \mathrm{~cm}$ field size, and two regions of penumbra, and the percentage of the dose in the field, in addition do dose uniformity was assessed. Each film scanned using digitizer scanner then treated by using image processing program (IDL) after converting the images into TIFF format as IDL input variable, where the field size and penumbra and the uniformity of radio therapy beam will be determined, accelerator for 
vertical and horizontal reading on The portal films, with SSD $=100 \mathrm{~cm}$ and the field size $10 \times 10 \mathrm{~cm}^{2}$ and isocentric set-up $0,90,180$, and 270 degrees, and the variables used to achieve these results. Aline were drowning through the images and line histogram was obtained in order to calculate the frequency of intensity difference throughout the (the line) filed. And the result showed that (Figure 1):

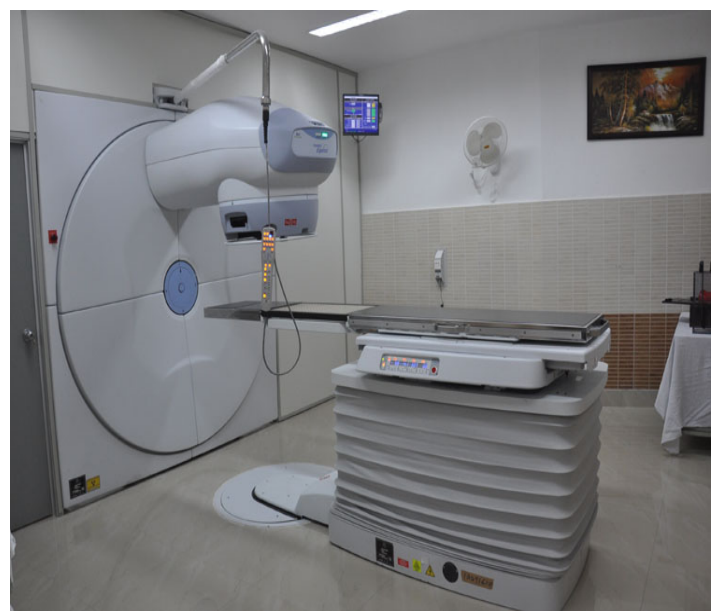

Figure 1. Illustration of $\mathrm{Co}^{60}$ machine.

\section{Result (Tables 1-4, Figure 2 \& Figure 3)}

Table 1. Measured field size and the percentage of the radiation received for all machines.

\begin{tabular}{ccc}
\hline Machine & Reference Filed $(10 \times 10) \mathrm{cm}$ & $\%$ \\
\cline { 2 - 3 } $\mathrm{Co}^{60}$ & $9.41766 \times 9.41766 \mathrm{~cm}$ & $94.2 \%$ \\
$\mathrm{Co}^{60}$ & $9.11417 \times 9.11417 \mathrm{~cm}$ & $91.142 \%$ \\
Linear & $10.0 \times 10.0 \mathrm{~cm}$ & $100 \%$ \\
Linear & $10.0 \times 10.0 \mathrm{~cm}$ & $100 \%$ \\
\hline
\end{tabular}

Table 2. Area reduced from reference field size.

\begin{tabular}{cc}
\hline Machine & Reduced area from the field size \\
\hline $\mathrm{Co}^{60}$ & $0.58234 \mathrm{~cm}$ \\
$\mathrm{Co}^{60}$ & $0.88583 \mathrm{~cm}$ \\
Linear & 0.0000 \\
Linear & 0.0000 \\
\hline
\end{tabular}

Table 3. Percentage of the field received radiation by $100 \%$.

\begin{tabular}{ccc}
\hline Machine & Dose percentage in the field & Dose percentage in the border of the field \\
\hline $\mathrm{Co}^{60}$ & $98.039 \%$ & $83.137 \%$ \\
$\mathrm{Co}^{60}$ & $94.118 \%$ & $89.02 \%$ \\
Linear & $78.431 \%$ & - \\
Linear & $78.431 \%$ & - \\
\hline
\end{tabular}


Table 4. Penumbra size.

\begin{tabular}{cc}
\hline Machine & Penumbra size \\
\hline $\mathrm{Co}^{60}$ & 1.224 \\
$\mathrm{Co}^{60}$ & 1.0363 \\
Linear & 0.4517 \\
Linear & 0.4637 \\
\hline
\end{tabular}

(Note: the figures presented here it's an example from one cobalt and one linear just)

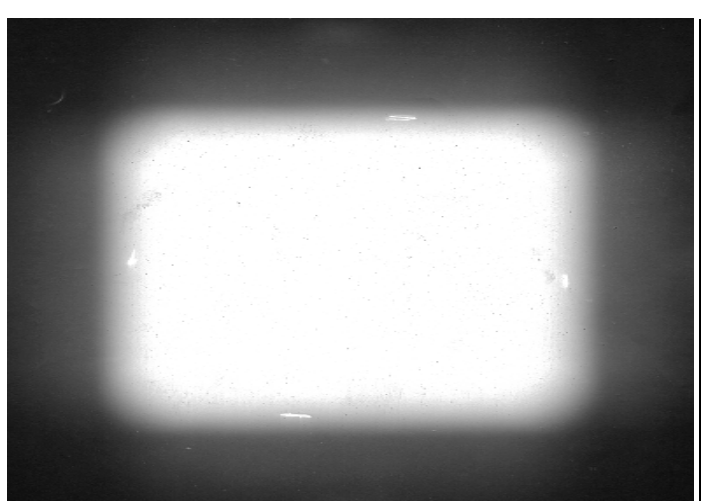

(a)

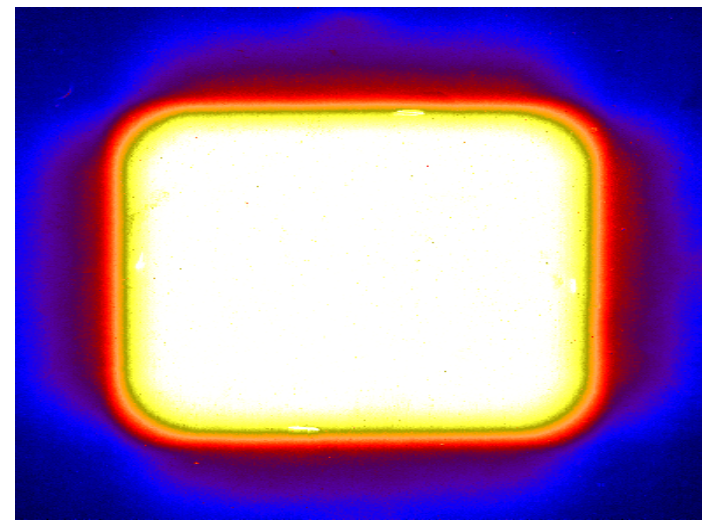

(c)

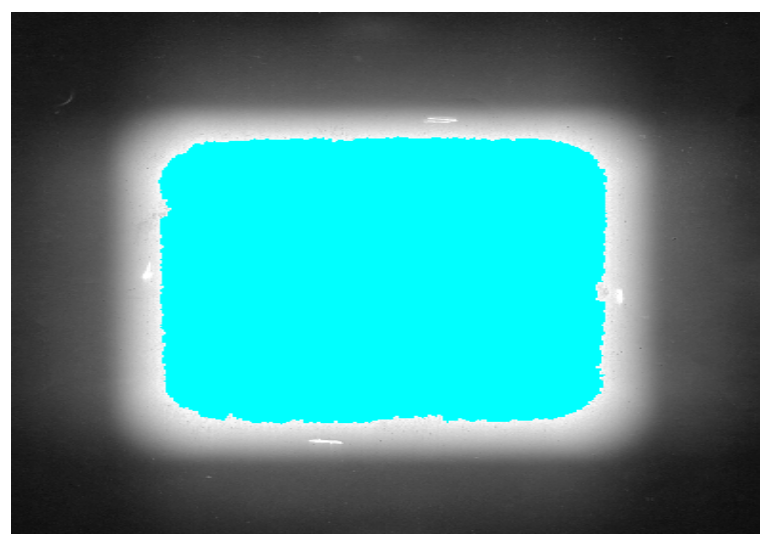

(e)

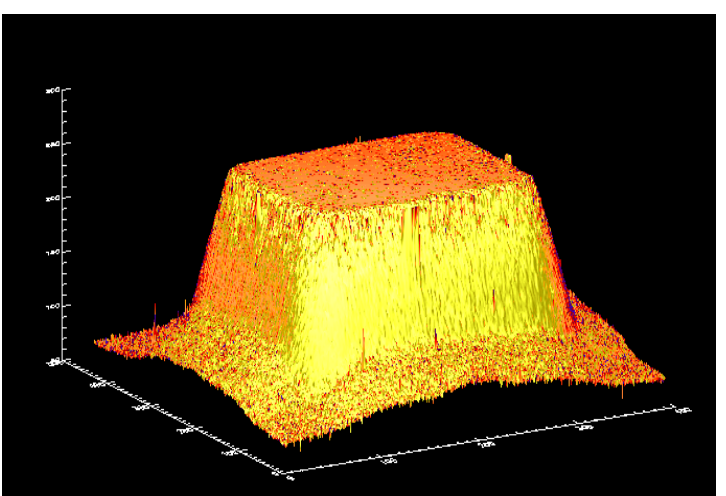

(b)

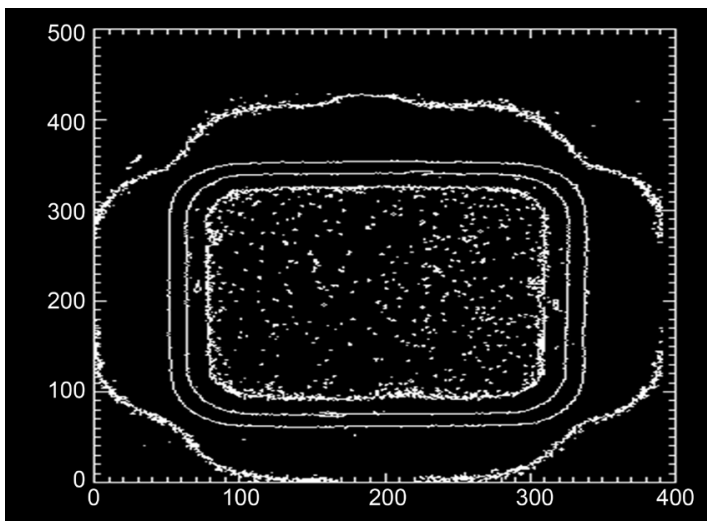

(d)

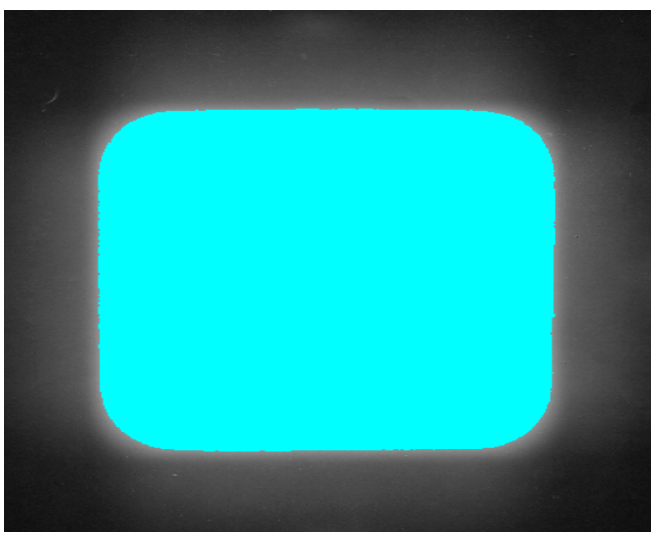

(f) 


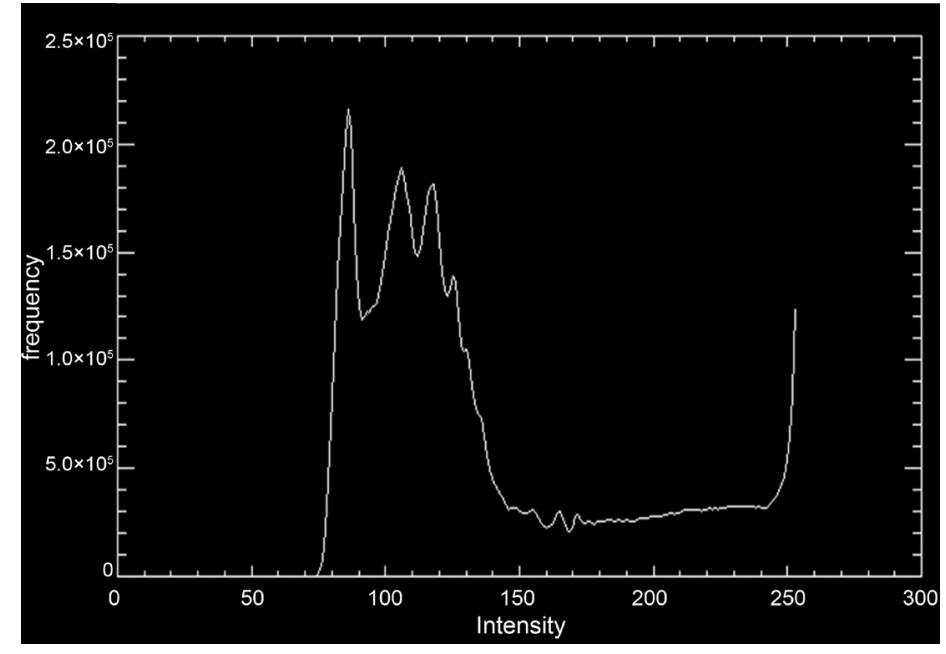

(g)

Figure 2. (a) Radiographic image with Co-60, Measured field size was $9.41766 \times 9.41766 \mathrm{~cm}, 94.1766 \%$; (b) Histogram showing the reduced area from the reference field size in Co-60 machine and it was $0.58234 \mathrm{~cm}$; (c) Field size $9.41766 \times 9.41766 \mathrm{~cm}, 94.1766 \%$ with white color, border of the field with yellow and penumbra region $1.224 \mathrm{~cm}$ with orange and red color; (d) Contour for the image; (e) Percentage of the dose in the field was $98.039 \%$ and in the border $83.137 \%$ for Co-60 machine; (f) The field size $10 \times 10 \mathrm{~cm}$; $(\mathrm{g})$ Histogram showing scatter and penumbra region.

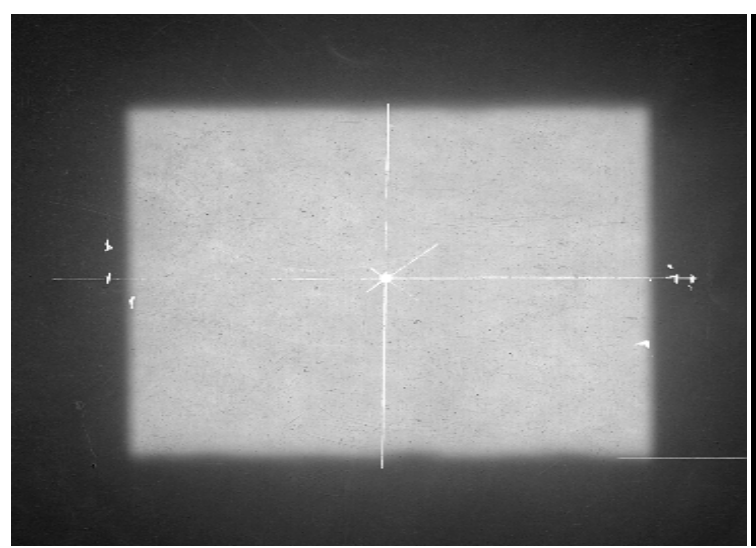

(a)

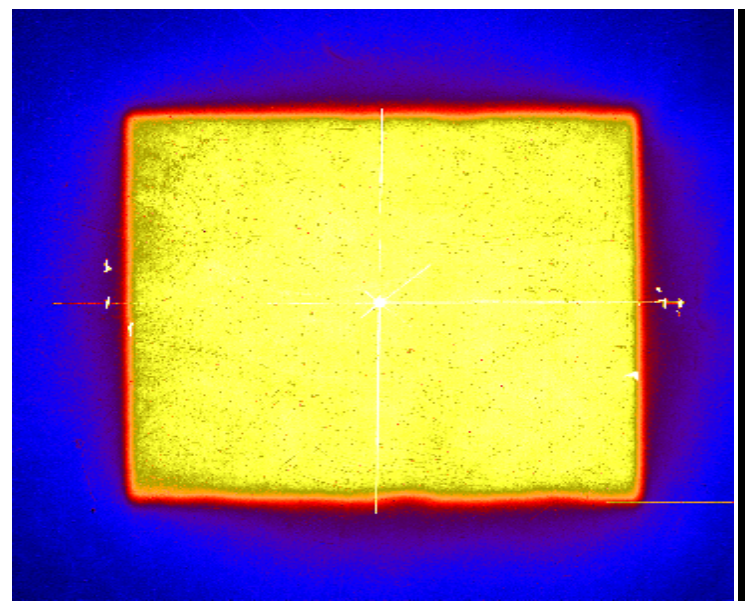

(c)

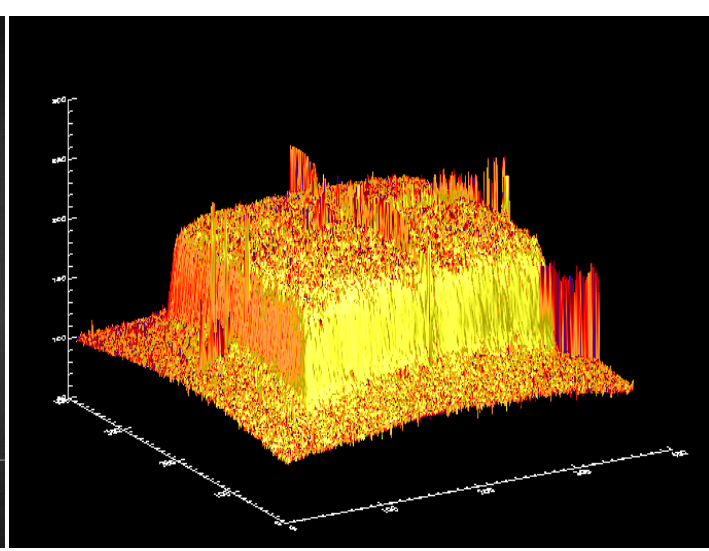

(b)

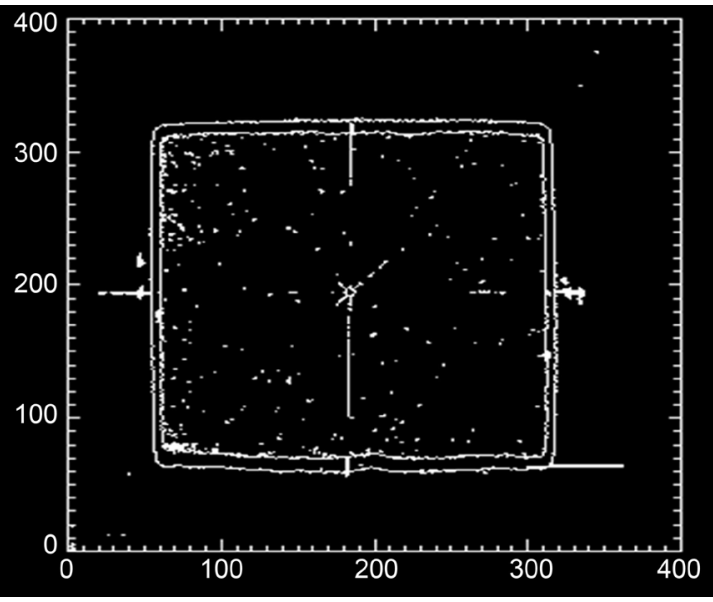

(d) 


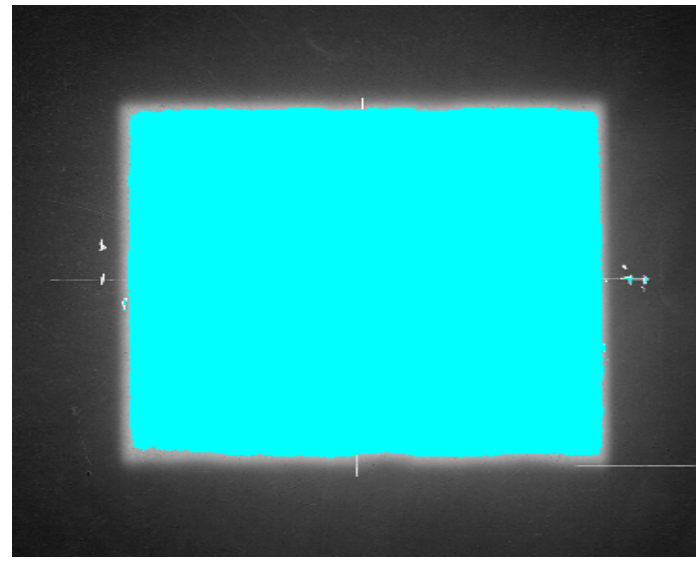

(e)

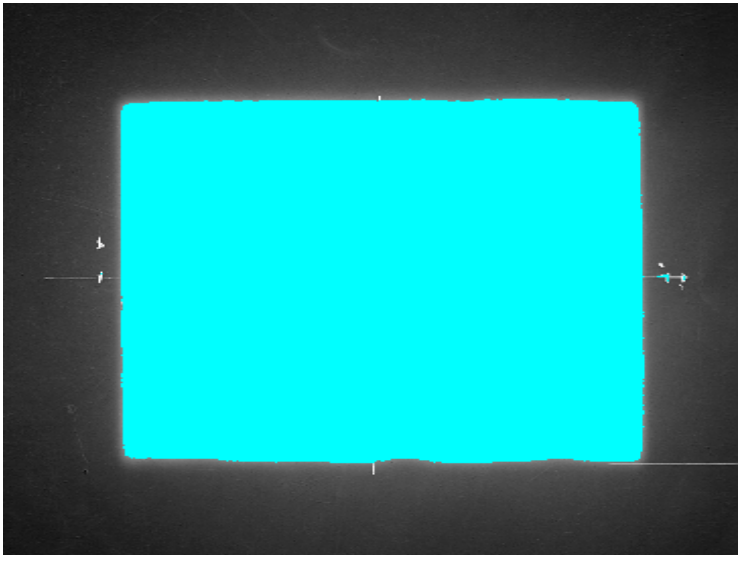

(f)

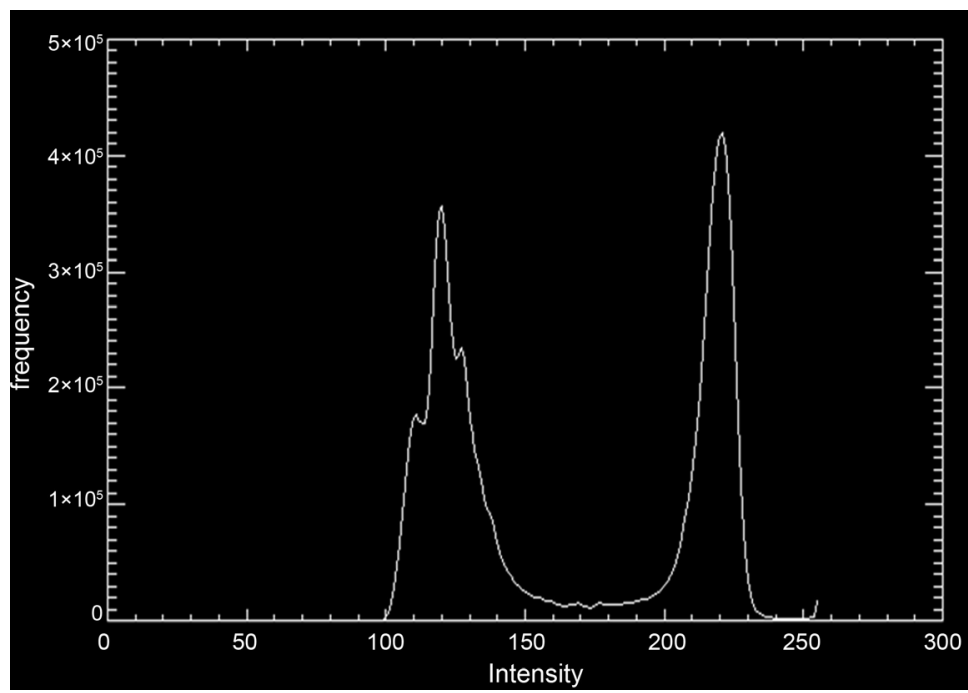

(g)

Figure 3. (a) Radiographic image with linear accelerator' measured field size was $10 \times 10$; (b) Histogram showing the reduced area from the reference field size for linear accelerator. Machine and it was $0.000 \mathrm{~cm}$; (c) Useful field size $10 \times 10 \mathrm{~cm}$ with white color, border of the field with yellow and penumbra region 0.4517 with orange and red color; (d) Contour for the image; (e) Percentage of the dose in the field was $78.431 \%$ and in the border $0.000 \%$. For linear accelerator machine; (f) The size $10 \times 10 \mathrm{~cm}$; $(\mathrm{g})$ Histogram showing scatter and penumbra region.

\section{Discussion}

This study performed to assess the radiotherapy beam by measuring the field size, penumbra size and the percentage of the field dose, the results of these study showed that the field size of two type of $\mathrm{Co}^{60}$ machine was $(9.4 \times 9.4) \mathrm{cm}$ and $(9.1 \times 9.1) \mathrm{cm}$ as in Table 1 . For each $\mathrm{Co}^{-}{ }^{60}$, the reduction in field size was $0.58234 \mathrm{~cm}$ (as Figure 2(b) in first type and $0.88583 \mathrm{~cm}$ (see Table 2) in the second one and its means that the verification light and field size doesn't matched and that due to adjustment error in the machine (mechanical error), for linear accelerator machines the field size was measured to be $10 \times 10 \mathrm{~cm}$ (Table 1) exactly as the reference field size, and there is no area reduced in linacs. Figure 3, Table 2.

The penumbra size for the two types of $\mathrm{Co}^{-}{ }^{60}$ machine was measured also as 
Garduñ et al. 2007, and Se An Oh et al., [7] studies, and it was $1.224 \mathrm{~cm}$ (Figure 2(c)) and $1.0363 \mathrm{~cm}$, and the penumbra size of the linear accelerator machines was found to be $0.4637 \mathrm{~cm}$ and $0.4517 \mathrm{~cm}$ (Table 4) as [8]. This difference in the size of the penumbra is totally clear as in Table 4 . Where the cobalt penumbra size was more than $1 \mathrm{~cm}$ but less than $0.5 \mathrm{~cm}$ in Linear accelerator, this overexpansion of the field can lead to excessive irradiation of normal tissue around the estimated field size for any kind of treatment and for any filed size, so in Co-60 can be manipulated according to the source size and acceptable activity required for treatment, the use of trimmer or half beam block may be helpful in Co- 60 . Also QC program in required time schedule should be carefully done.

The area of the field that received radiation by $100 \%$ as [9] study was measured and it was $94.1 \%$ and $91.1 \%$ in $\mathrm{Co}^{60}$ and $100 \%$ for linear accelerator machine and that means linacs. Machines deliver $100 \%$ of the dose to the useful field size. The dose percentage in the field for Co-60 was $98.0 \%$ and $94.1 \%$ and thus the dose in the border of field $83.1 \%$ and $89.0 \%$ and it's different in linacs because the dose percentage in the field was $78.431 \%$ and $78.431 \%$ and there is no measurable dose outside the field size of linacs. As in Figure 3(e) (Table 3).

\section{Conclusions}

The process of treatment using high energy of radiation carries a great risk for normal tissue damage, where high quality of radiation is used.

Penumbra is unwanted projectile distance at the edge of the beam which is harmful to normal tissue around the FS. This study reveals that $\mathrm{CO}^{60}$ machine has a large size of penumbra rather than the linear accelerator should be considered in treatment carrying a great amount of normal tissue or low tolerance to radiation.

This study concludes that linear accelerator is more precise than $\mathrm{Co}^{60}$ in term of lateral distance from the edge of the field. Also using the image processing program is more accurate in estimation of dose uniformity and linearity that the conventional portal film method, where the distance is measured randomly, can represent these measured values numerically and graphically.

\section{Conflicts of Interest}

The authors declare no conflicts of interest regarding the publication of this paper.

\section{References}

[1] Green, D.T. and Ferrington, R.F. (1952) 1000 Curie Cobalt Units for Radiation Therapy. III. Design of a Cobalt 60 Beam Therapy Unit. British Institute of Radiology, 25, 309-313. https://doi.org/10.1259/0007-1285-25-294-309

[2] Johns, H., et al. (1951) 1,000-Curie Cobalt-60 Units for Radiation Therapy. Nature, 168, 1035.

[3] Mayles, P., Nahum, A.E. and Rosenwald, J.-C. (2007) Handbook of Radiotherapy Physics: Theory and Practice. CRC Press, Boca Raton. 
https://doi.org/10.1201/9781420012026

[4] Khan, F.M. and Gibbons, J.P. (2014) Khan's the Physics of Radiation Therapy. Lippincott Williams \& Wilkins, Philadelphia.

[5] Abdallah, Y.M. and Boshara, M.A. (2014) Assessment of Field Size on Radiotherapy Machines Using Texture Analysis. Sudan Medical Monitor, 9, 5. https://doi.org/10.4103/1858-5000.144642

[6] Leszczynski, K.W., Shalev, S. and Gluhchev, G. (1993) Verification of Radiotherapy Treatments: Computerized Analysis of the Size and Shape of Radiation Fields. Medical Physics, 20, 687-694. https://doi.org/10.1118/1.597017

[7] Oh, S.A., et al. (2012) Study of the Penumbra for High-Energy Photon Beams with Gafchromic $^{\text {TM }}$ EBT2 Films. Journal of the Korean Physical Society, 60, 1973-1976. https://doi.org/10.3938/jkps.60.1973

[8] Cheung, T., Butson, M.J. and Yu, P.K. (2006) Measurement of High Energy X-Ray Beam Penumbra with Gafchromic ${ }^{\mathrm{Tm}}$ EBT Radiochromic Film. Medical Physics, 33, 2912-2914. https://doi.org/10.1118/1.2218318

[9] Kron, T., Elliott, A. and Metcalfe, P. (1993) The Penumbra of a 6-MV X-Ray Beam as Measured by Thermoluminescent Dosimetry and Evaluated Using an Inverse Square Root Function. Medical Physics, 20, 1429-1438.

https://doi.org/10.1118/1.597157 